\title{
Herbal compound "Songyou Yin" reinforced the ability of interferon-alfa to inhibit the enhanced metastatic potential induced by palliative resection of hepatocellular carcinoma in nude mice
}

Xiu-Yan Huang ${ }^{1,3+}$, Zi-Li Huang ${ }^{2,3{ }^{\dagger}}$, Lu Wang ${ }^{3+}$, Yong-Hua Xu ${ }^{2}$, Xin-Yu Huang ${ }^{1}$, Kai-Xing Ai ${ }^{1}$, Qi Zheng ${ }^{1}$, Zhao-You Tang ${ }^{3 *}$

\begin{abstract}
Background: Liver resection is a widely accepted treatment for hepatocellular carcinoma (HCC). Our previous clinical study showed that the rate of palliative resection was 34.0\% (1958-2008, 2754 of 8107). However, the influence of palliative resection on tumor metastasis remains controversial. The present study was conducted to evaluate the effect of palliative resection on residual HCC and to explore interventional approaches.

Methods: Palliative resection was done in an orthotopic nude mice model of HCC (MHCC97H) with high metastatic potential. Tumor growth, invasion, metastasis, lifespan, and some molecular alterations were examined in vivo and in vitro. Mice that underwent palliative resection were treated with the Chinese herbal compound "Songyou Yin," interferon-alfa-1b (IFN- $\alpha$ ), or their combination to assess their effects.

Results: In the palliative resection group, the number of lung metastatic nodules increased markedly as compared to the sham operation group $(14.3 \pm 4.7$ versus $8.7 \pm 3.6, P<0.05)$; tumor matrix metalloproteinase 2 (MMP2) activity was elevated by 1.4 -fold, with up-regulation of vascular endothelial growth factor (VEGF) and downregulation of tissue inhibitor of metalloproteinase 2 (TIMP2). The sera of mice undergoing palliative resection significantly enhanced cell invasiveness by 1.3-fold. After treatment, tumor volume was $1205.2 \pm 581.3 \mathrm{~mm}^{3}, 724.9$ $\pm 337.6 \mathrm{~mm}^{3}, 507.6 \pm 367.0 \mathrm{~mm}^{3}$, and $245.3 \pm 181.2 \mathrm{~mm}^{3}$ in the control, "Songyou Yin," IFN- $\alpha$, and combination groups, respectively. The combined therapy noticeably decreased the MMP2/TIMP2 ratio and prolonged the lifespan by $42.2 \%$. Moreover, a significant $(P<0.001)$ reduction of microvessel density was found: $43.6 \pm 8.5,34.5 \pm$ $5.9,23.5 \pm 5.6$, and $18.2 \pm 8.0$ in the control and treatment groups, respectively.

Conclusion: Palliative resection-stimulated HCC metastasis may occur, in part, by up-regulation of VEGF and MMP2/TIMP2. "Songyou Yin" reinforced the ability of IFN- $\alpha$ to inhibit the metastasis-enhancing potential induced by palliative resection, which indicated its potential postoperative use in patients with HCC.
\end{abstract}

\footnotetext{
* Correspondence: zytang88@163.com

+ Contributed equally

${ }^{3}$ Liver Cancer Institute and Zhongshan Hospital, Fudan University, Shanghai 200032, PR China; Key Laboratory for Carcinogenesis \& Cancer Invasion, the

Chinese Ministry of Education, Shanghai 200032, PR China

Full list of author information is available at the end of the article
} 


\section{Background}

Hepatocellular carcinoma (HCC) is the third most common cause of cancer-related deaths worldwide [1]. Liver resection is a widely accepted treatment modality for HCC; at the authors' institution, 53 patients with $\mathrm{HCC}$ with a 20year survival all underwent curative resection [2]. However, the influence of liver resection on tumor growth and metastasis remains controversial. Increasing numbers of reports indicate that partial hepatectomy accelerates tumor growth and stimulates tumor metastasis [3-7], although one report claimed that major hepatic resection may suppress the growth of tumors remaining in the residual liver [8]. Another report indicated that hepatectomy prolongs survival of mice with induced liver metastases [9]. Finally, a report demonstrated that surgical therapy is associated with improved survival in patients with HCC [10].

Data from authors' institution (1958-2008, unpublished) revealed that the 5-year survival after palliative HCC resection (30.0\%, $n=2754)$ was much lower than that following curative resection $(52.6 \%, n=5353)$. The clinical observation that patients with $\mathrm{HCC}$ receiving palliative resection (with grossly identified residual cancer) experienced dramatically increased metastases implies that palliative resection may enhance the metastatic potential of HCC, which is poorly understood to the best of our knowledge. Therefore, this study aimed to verify whether palliative resection enhances invasion and metastatic potential of residual HCC and to explore a novel approach for therapeutic intervention.

An orthotopic human HCC model in nude mice with high metastatic potential, which was established at the authors' institution, was used [11-13]. Our previous study showed that interferon-alfa-1b (IFN- $\alpha$ ) [14] and the herbal extract "Songyou Yin [15]" (SYY) inhibit HCC growth, metastasis, and recurrence and prolong survival in the nude mice model system. Consequently, these two agents were used for this interventional study.

\section{Methods}

Animals

Male athymic BALB/c nu/nu mice, weighing 18-20 g at 5 weeks of age, were obtained from the Shanghai Institute of Materia Medica, Chinese Academy of Science. All mice were handled according to the recommendations of the National Institutes of Health Guidelines for Care and Use of Laboratory Animals. The experimental protocol was approved by the Shanghai Medical Experimental Animal Care Committee.

\section{HCC cell line and metastatic orthotopic tumor model in nude mice}

At the authors' institution, a stepwise metastatic human HCC model system was established, which included a metastatic HCC model in nude mice LCI-D20 [11], an
HCC cell line MHCC97 with high metastatic potential that originated from LCI-D20 tumor [12], and cell clone MHCC97H from its parent MHCC97, with a lung metastatic rate up to $100 \%$ using orthotopic inoculation [13]. Human HCC tumor models produced by MHCC97H were established in nude mice by orthotopic inoculation, as described previously [15]. The MHCC97H cells were maintained in Dulbecco modified Eagle medium (DMEM, Gibco-BRL, Gaithersburg, MD) without any antibiotic. HCC cell lines of HCCLM3 with higher invasiveness and HCC7721, HCC7402, and Hep3B with very low invasiveness were also prepared.

\section{Drugs}

The Chinese herbal medicine formula "Songyou Yin" (SYY), a dietary component authorized by the Chinese State Food and Drug Administration (Grant No. G20070160), was originally designed to promote vital energy and to be considered as a nontoxic therapeutic supplement for cancer patients [15]. The mixture includes five Chinese medicinal herbal extracts, whose proportions $(\mathrm{w} / \mathrm{w})$ are as follows: Salvia miltiorrhiza Bge., 14.3\%; Astragalus membranaceus Bge., 14.3\%; Lycium barbarum L., 23.8\%; Crataegus pinnatifida Bge., 23.8\%; and Trionyx sinensis Wiegmann, 23.8\% (all from China). The ethanol extract was prepared as follows: The dried and pulverized medicinal herbs were mixed together, and each batch was poached twice for a total of $3 \mathrm{~h}$, then filtrated, concentrated, and soaked with ethanol for $12 \mathrm{~h}$. Finally, SYY, with the level of relative density $1.36\left(60^{\circ}-80^{\circ} \mathrm{C}\right)$, was obtained and stored at $4^{\circ} \mathrm{C}$ before application in experiments. The SYY used in the in vitro and in vivo studies, with the same batch number (\#060601), was produced by the Caitong Detang Chinese Traditional Medicine Pharmaceutical Factory, Shanghai, China. A $120-\mathrm{mg} / \mathrm{mL}$ sterilized SYY by two filtrations was prepared and then diluted cell culture medium or distilled water for further use. High-performance liquid chromatography (HPLC) fingerprinting of SYY and its five characteristic components was carried out by the Shanghai Institute of Materia Medica (SIMM), Chinese Academy of Sciences (CAS), China. The compound was diluted with distilled water for further use, which inhibits $\mathrm{HCC}$ cell lines MHCC97H with high invasive potential and Hep3B cells with very low invasiveness in vitro and inhibits $\mathrm{HCC}$ growth and metastasis in vivo [15]. Recombinant IFN- $\alpha$ (Sinogen, Kexing Bioproduct Company Ltd, Shenzhen, P.R. China) inhibits HCC, which may be attributable to anti-angiogenesis $[14,16]$.

\section{Mice grouping and treatment}

This study comprised 120 nude mice. In the first experiment, 48 nude mice bearing HCC xenografts were randomized into two groups 14 days after orthotopic 
implantation (24 mice/group), including a palliative resection group of mice undergoing partial HCC resection with preservation of $2 \mathrm{~mm}$ tumor [17] and a sham operation group (control) of mice having only exposure of the liver but no resection. In the second experiment, another 72 nude mice (14 days after orthotopic implantation) undergoing palliative resection were randomized into four groups according to the different therapies (18 mice/group). Therapy started on day 2 after palliative resection.

Control group mice each received $0.3 \mathrm{~mL}$ of distilled water via the oral gavage method once a day and were injected with sterile saline water (NS, $0.1 \mathrm{~mL}$, subcutaneously) daily for 5 consecutive weeks 24 hours after resection.

Each mouse in the SYY group received $0.3 \mathrm{~mL}$ of "Songyou Yin" ( $3.6 \mathrm{~g} / \mathrm{kg} / \mathrm{d} /$ mouse) via the oral gavage method [15] and NS, $0.1 \mathrm{~mL}$, subcutaneously daily.

The mice in the IFN- $\alpha$ group received $0.3 \mathrm{~mL}$ of distilled water via the oral gavage method and $0.1 \mathrm{~mL}$ of IFN- $\alpha$ (7.5 $\times 10^{6} \mathrm{U} / \mathrm{kg} / \mathrm{d} /$ mouse), subcutaneously daily [14].

Finally, the SYY + IFN- $\alpha$ group received the combined therapy with "Songyou Yin" and IFN- $\alpha$ as described for the groups given each agent alone.

\section{Parameters observed}

In the first experiment, 6 mice of each group were humanely killed by cervical dislocation 35 days after palliative resection to detect pulmonary metastasis. The remaining mice (18/group) were kept alive and their lifespan was determined starting from the day of resection; the rate of prolonged life was calculated as done previously [15]. The in situ activities of membrane type 1-matrix metalloproteinase (MT1-MMP), matrix metalloproteinase 2 (MMP2), and protein levels of MMP2, tissue inhibitor of metalloproteinase 2 (TIMP2), vascular endothelial growth factor (VEGF), and endostatin in the grown tumors obtained from the implantation sites were determined.

In the second experiment, daily general observations and weekly body weights (BWs) of the mice were recorded; 6 mice from each group were humanely killed 48 hours after the final treatment. Tumor size was measured with calipers and volume was estimated by the formula $V=\mathrm{L} \times \mathrm{H} \times \mathrm{W} \times 0.5236$; the tumor inhibition rate was calculated [15]. The remaining 12 mice of each group were maintained on the designated therapies until death to determine their lifespan. Lung metastases, MMP2 activity, protein levels of MMP2, TIMP2, and VEGF, and microvessel density (MVD) were determined.

\section{Samples prepared}

Serum, lung tissues, tumor tissues, and their protein extracts were harvested for in vitro and in vivo studies.

\section{In vitro invasion and migration assays}

The cells of MHCC97H, HCCLM3, HCC7721, HCC7402, and Hep3B treated with serum from killed mice and cell culture medium supplemented with $10 \%$ human $A B$ serum (control) for 72 hours were added to the upper chamber $\left(100 \mu \mathrm{L}\right.$ DMEM, $5 \times 10^{4}$ cells/well $)$ and $600 \mu \mathrm{L}$ conditioned medium was added to the lower chamber. The invaded cells were fixed with methanol and stained with crystal violet solution after a 24-hour incubation. The migration assay was similar to the invasion assay, only without Matrigel. The results were expressed as the number of penetrated cells under microscope at $\times 200$ magnification on five random fields and were presented as means \pm SD of three assays [13].

\section{Hematoxylin and eosin stains}

Paraffin blocks of $10 \%$ buffered formalin-fixed samples of tumor and lung tissues were prepared, serial sections were cut at $5 \mu \mathrm{m}$, and pulmonary metastatic nodules were verified with hematoxylin and eosin stain [18].

\section{MT1-MMP activity assay}

The MT1-MMP activity assay kit (Amersham Biosciences, Buckinghamshire, UK) was used to detect active endogenous MT1-MMP in tissue extracts with analytical sensitivity of $0.7 \mathrm{ng} / \mathrm{mL}$. The resultant color was read at $405 \mathrm{~nm}$ using an automated microplate reader (BioTek Instrument, Winooski, VT). The concentration of active MT1-MMP in the samples was determined by interpolation from a standard curve.

\section{Gelatin zymography assay}

MMP2 activity in tumor tissue lysate was measured via Gelatin zymography assay [15]. The MMP activity was visualized as white proteolysis bands against the gel stained with Coomassie blue. The molecular weights of these bands indicating MMP2 activity were determined by molecular weight standards (Bio-Rad Laboratories, Hercules, CA). The relative MMP activity was quantitated by scanning the zymogram photograph on a gel documentation and analysis system (Alphalmager 2000, Alpha Innotech, San Leandro, CA). The area and optical density of each band was calculated and normalized by its own internal control; the digitized data of photographs presenting MMP2 activities in the control group were considered as $100 \%$.

\section{Enzyme-linked immunosorbent assay}

Protein levels of MMP2, TIMP2, VEGF, and endostatin in tumor extracts were measured via commercial available MMP2 (R\&D Systems, Minneapolis, MN), TIMP2 (Amersham Biosciences, Buckinghamshire, UK), VEGF enzyme-linked immunosorbent assay (ELISA; R\&D 
Systems, Minneapolis, MN), and endostatin (Chemicon International, Temecula, CA) kits. The mean of minimum detectable dose of MMP2, TIMP2, VEGF, and endostatin is $0.16 \mathrm{ng} / \mathrm{mL}, 3.2 \mathrm{ng} / \mathrm{mL}, 5 \mathrm{pg} / \mathrm{mL}$, and 1.95 $\mathrm{ng} / \mathrm{mL}$, respectively. Absorbance was measured at 450 $\mathrm{nm}$, using a microplate spectrophotometer with the correction wavelength of $570 \mathrm{~nm}$. The assays were conducted in triplicate.

\section{MMP2 activity detected by ELISA}

MMP2 activity was quantitated with a human MMP2 Activity ELISA System (Amersham Pharmacia Biotech, Piscataway, NJ) according to the manufacturer's instructions. The plate was read at $450 \mathrm{~nm}$ in a SPECTRAmax 250 Microplate Spectrophotometer (Molecular Devices, Sunnyvale, CA). The assays were conducted in triplicate.

\section{Immunohistochemistry assay}

MVD (using CD34 immunostaining) was counted [19]. All slides were independently assessed by two board-certified pathologists who were blinded to the experiment. Any difference in the microvessel count was resolved by consensus.

\section{Statistical analysis}

Data were analyzed by the statistical SAS software package (SAS 8.2) using ANOVAs, Student $t$ test, and Kaplan-Meier method (log-rank test). All continuous variables were expressed as means \pm SD or means \pm SE. Statistical significance was set at $P<0.05$.

\section{Results}

Palliative resection prolongs survival but increases lung metastases in nude mice with HCC

Increased pulmonary metastases were found in the palliative resection group (Figure 1A, left) as compared to the control (Figure 1A, right). The number of lung metastatic nodules was $14.3 \pm 4.7$ versus $8.7 \pm 3.6(P<$ 0.05 , Figure 1B). However, the lifespan was longer in the palliative resection group compared with that in the control group $(60.8 \pm 2.7 \mathrm{~d}$ versus $51.3 \pm 1.4 \mathrm{~d}$, means \pm SE, $P<0.05)$.

We found that cells $(\mathrm{MHCC} 97 \mathrm{H})$ treated with serum from the palliative resection group (Figure 1C, left) presented the most invasive potential through Matrigel as compared to cells in controls (Figure 1C, right), with invasive ability increased by $25.7 \%$ (46.9/37.3, 1.3fold, $P<0.05$, Figure 1D), which was intervalidated by several HCC cell lines (HCCLM3, HCC7721, HCC7402, and Hep3B). However, no significant differences were found in migration capacity of treated cells among groups.
Palliative resection enhances MMP2 activity, elevates tumor protein levels of MMP2 and VEGF, and downregulates TIMP2 in situ

Gelatin zymography assays clearly showed that tumor MMP2 activity was stronger in the palliative resection group (Figure 2A1); the normalized optical density of the band presenting MMP2 activity was significantly elevated (1.4-fold, $P<0.01$, Figure 2A2), in accord with upregulation of the MMP2 protein level in the palliative resection group, that is, $73.7 \pm 8.0 \mathrm{ng} / \mathrm{mg}$ versus $57.9 \pm$ $10.1 \mathrm{ng} / \mathrm{mg}(P<0.01$, Figure 2A3). TIMP2 was downregulated with reductions in TIMP2 levels to $15.6 \%$ of control levels $(P<0.05$, Figure $2 \mathrm{~B})$. Tumor VEGF levels were also up-regulated by palliative resection, being $185.7 \pm 13.6 \mathrm{pg} / \mathrm{mg}$ versus $164.5 \pm 12.5 \mathrm{pg} / \mathrm{mg}(P<$ 0.05 , Figure $2 \mathrm{C}$ ). However, the alteration of activated tumor MT1-MMP and endostatin levels did not reach statistical significance between the two groups.

The combined therapy averts cancer-related BW loss and reinforces antitumor effects in nude mice model

SYY inhibited the BW loss, IFN- $\alpha$ was not obviously related to the BW loss, but the combined therapy noticeably minimized the BW loss, with the maximum statistical difference of BW among groups observed at the fifth week after treatment (Figure 3A). Tumor volumes in the control, SYY, IFN- $\alpha$, and SYY + IFN- $\alpha$ groups were $1205.2 \pm 581.3 \mathrm{~mm}^{3}, 724.9 \pm 337.6 \mathrm{~mm}^{3}$, $507.6 \pm 367.0 \mathrm{~mm}^{3}$, and $245.3 \pm 181.2 \mathrm{~mm}^{3}$, respectively $(P<0.001$, for the SYY + IFN- $\alpha$ group compared with control, Figure 3B1,2), with tumor inhibition rates of $39.9 \%$ (SYY group), $57.9 \%$ (IFN- $\alpha$ group), and $79.6 \%$ (SYY + IFN- $\alpha$ group). At the end of the fifth week, the mean number of lung metastatic nodules was reduced by $12.3 \%, 46.4 \%$, and $67.4 \%$, respectively, compared to the control (Figure $3 \mathrm{C}$ ). The lifespan was significantly extended in treatment groups (Figure 3D), and the rate of prolonged life was $42.2 \%$ in the SYY + IFN- $\alpha$ group.

\section{Inhibitory effect of therapies correlates to the inhibition of MMP2 and VEGF}

Our data revealed that both tumor MMP2 activity (Figure 4A1) and MMP2 (Figure 4A2) and VEGF (Figure 4C) protein levels were significantly down-regulated in treatment groups, whereas TIMP2 (Figure 4B) levels were up-regulated when compared to the controls. According to the inhibitory effects of SYY and IFN- $\alpha$, we found that SYY was more effective on MMP2 (Figure $4 \mathrm{~A} 1,2), \mathrm{IFN}-\alpha$ was more effective on VEGF (Figure $4 \mathrm{C}$ ), and the combined therapy was more effective than any agent alone. On the other hand, tumor MVD (Figure 4D1) decreased in the treated groups, being $34.5 \pm 5.9$, 

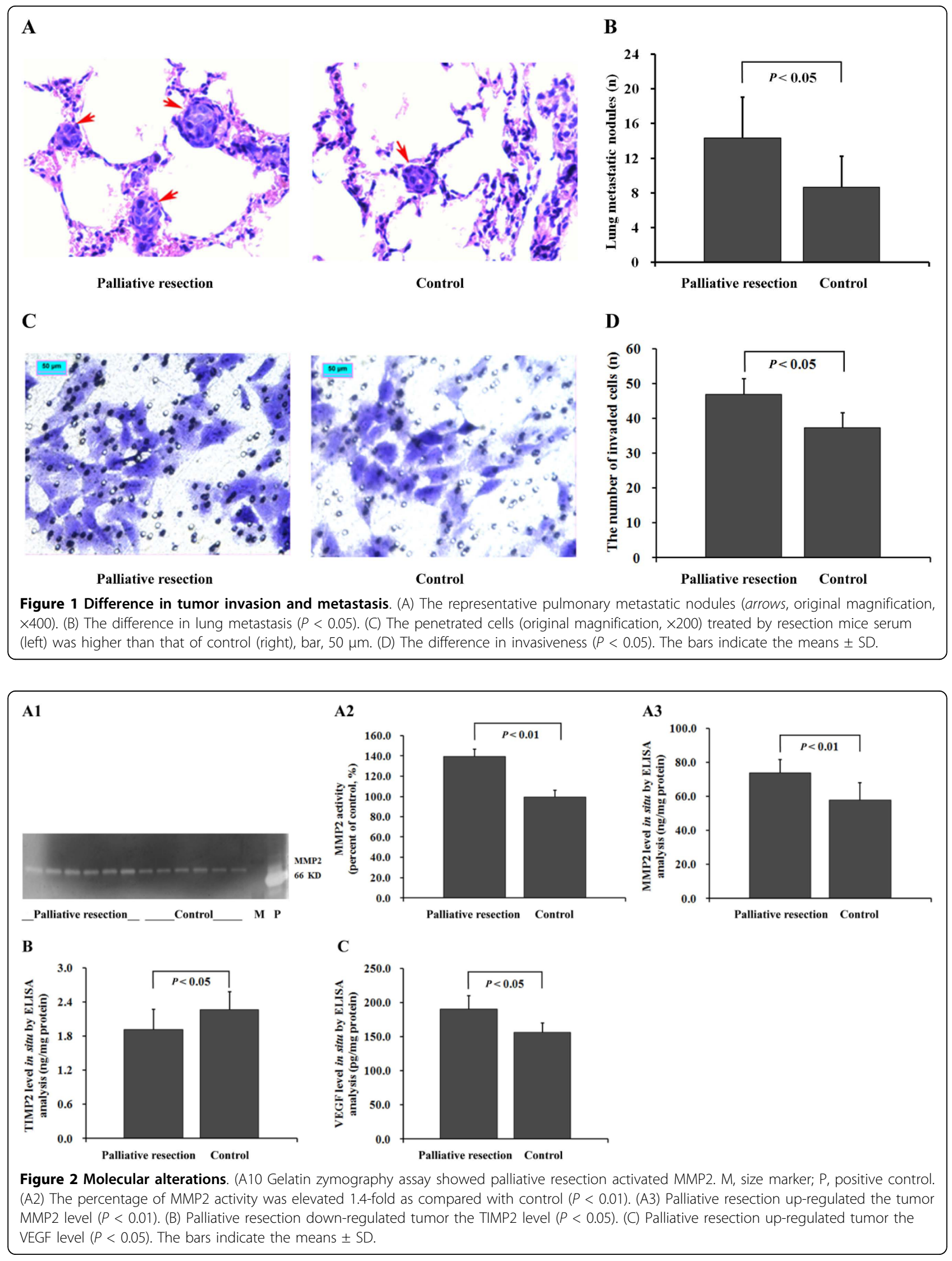


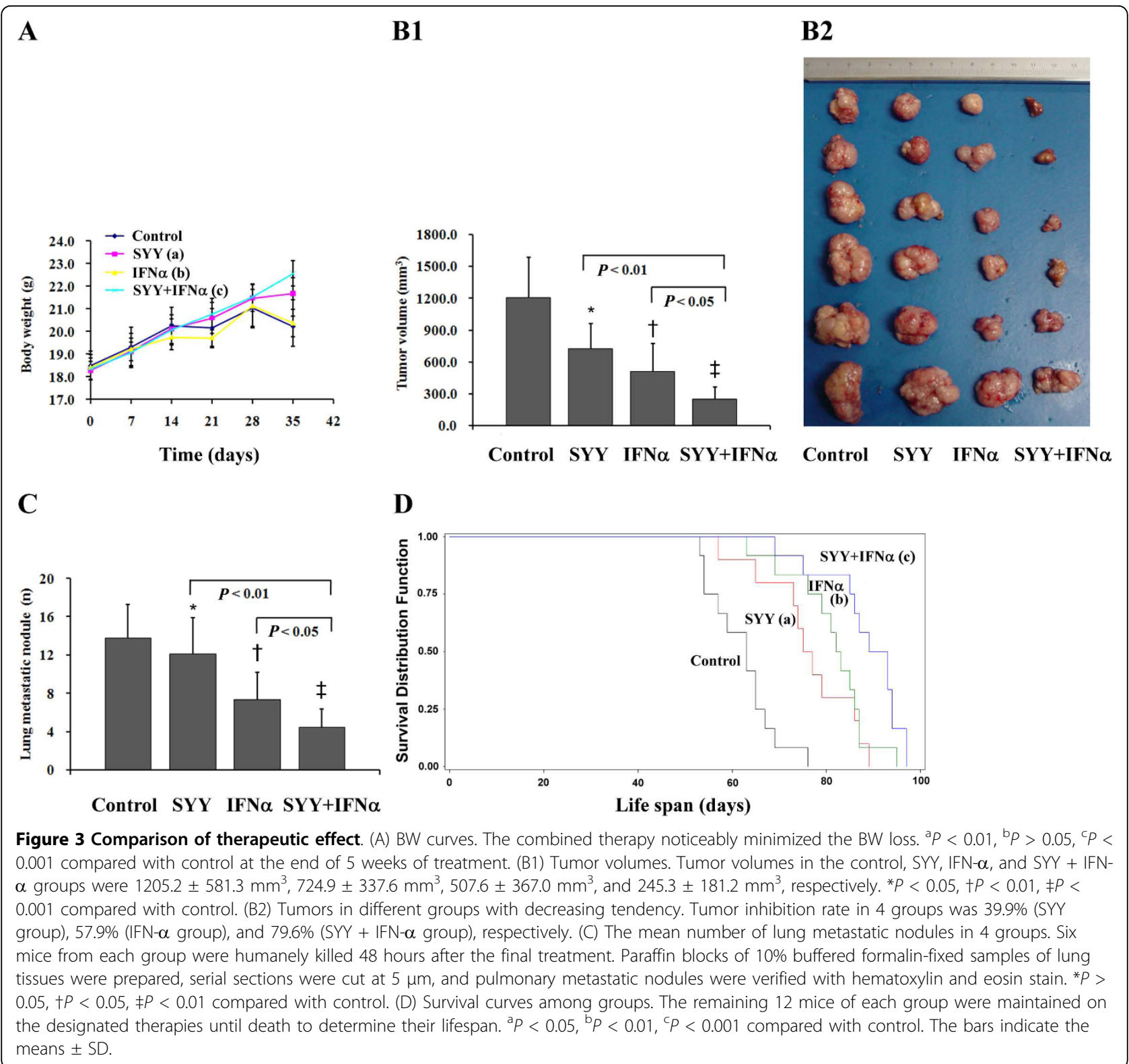

$23.5 \pm 5.6$, and $18.2 \pm 8.0$, respectively, as compared to control $(43.6 \pm 8.5, P<0.001$, Figure 4D2).

No animal experienced therapy-related side effects, BW loss of $>10 \%$, anemia, neutropenia, thrombocytopenia, or abnormal serum transaminases after the treatment regimen in this study (data not shown).

\section{Discussion}

Hepatectomy is a standard treatment for patients with HCC $[2,10]$. However, even in patients undergoing curative resection, the procedure is only potentially curative due to the existence of tumor cells or clinically undetectable residual intrahepatic lesions [2,3]. Our clinical observation showed that after palliative resection the patients experienced dramatically increased metastases without systemically effective treatments from the oncologic standpoint. However, several studies have demonstrated survival benefits from palliative liver resection [20-23]. Thus, the effectiveness of palliative resection for HCC remains controversial. This study was designed to evaluate the progression of residual tumor after palliative resection and to explore an interventional approach in a high metastatic human HCC model system that has been successfully used for studies of HCC-related invasion, metastasis [23], and screening of therapeutic agents for $\mathrm{HCC}[14,15,18,24]$.

Palliative resection has been applied to treat HCC and produced marked survival benefits when combined with 


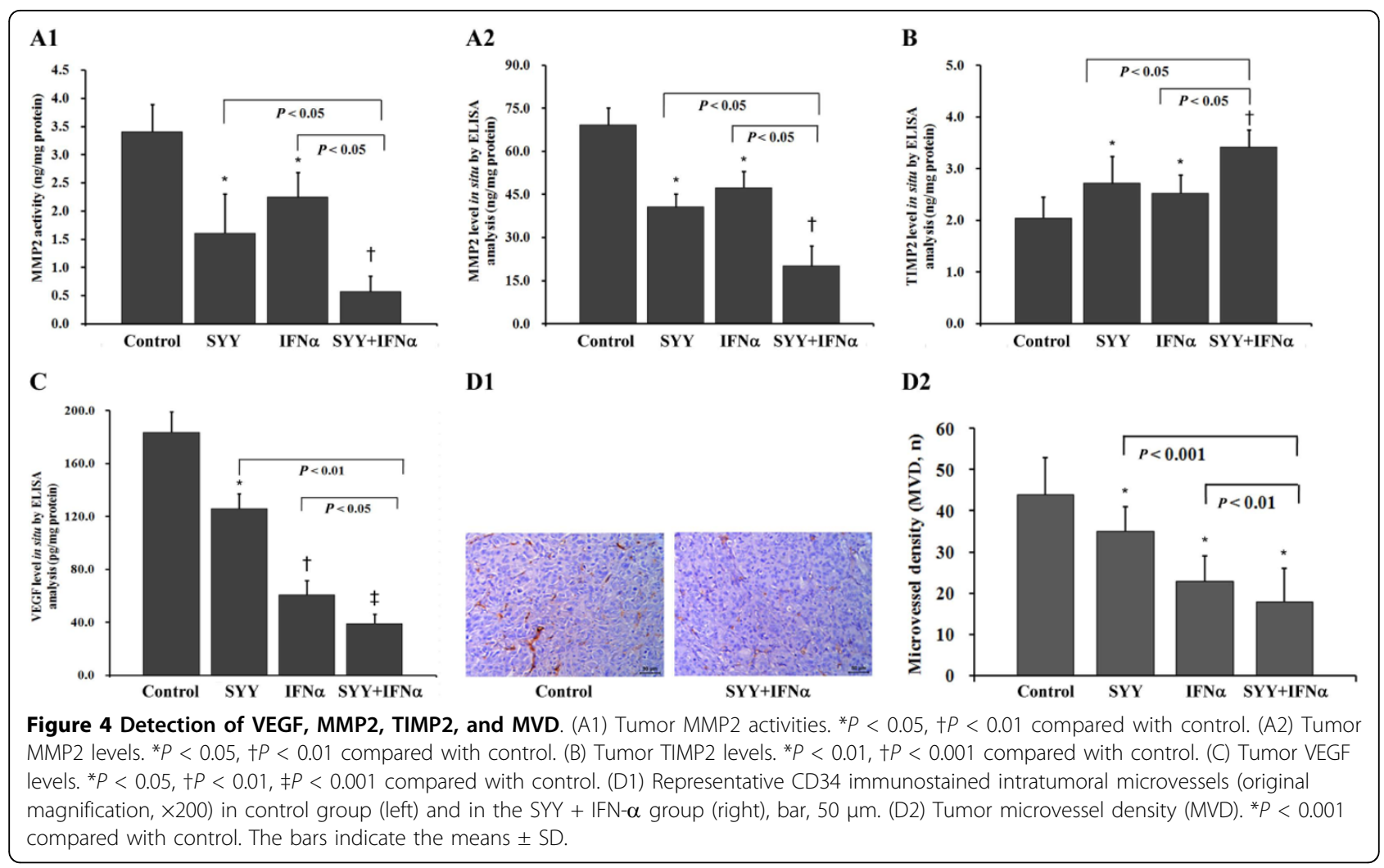

adjunct IFN- $\alpha / 5$-fluorouracil therapy [21,22]. It has been postulated that the survival prolongation after palliative resection may be partially due to tumor-debulking surgery [21]. In this study, therefore, we investigated the benefit from palliative resection in nude mice bearing human HCC and found the lifespan was $60.8 \pm 2.7$ days in palliative resection compared with $51.3 \pm 1.4$ days in controls. Our result was consistent with previous reports $[21,22]$, which implied that patients with HCC could benefit from palliative resection. In contrast, some studies have reported that partial hepatectomy accelerates tumor growth and stimulates tumor metastasis [3-7]. Our experimental research revealed that palliative resection is followed by acceleration of metastatic processes in the lungs. The increased pulmonary metastatic nodules were found in the palliative resection group $(14.3 \pm 4.7)$ compared to controls $(8.7 \pm 3.6)$, which may be partially due to breakdown of tumor MMP2/ TIMP2 balance and in situ up-regulation of VEGF that was consistent with a recent report that confirmed increased VEGF transcription in residual HCC after hepatectomy in a small animal model [25].

The higher ratio of MMP/TIMP has been related to a poorer prognosis in HCC [26]. Our data revealed that palliative resection activated MMP2 and downregulated TIMP2. Lower TIMP2 levels might cause MMP2 activation, which resulted in degradation of the extracellular matrix and increased angiogenesis. VEGF, a potent stimulator of tumor angiogenesis, is believed to have a major role in HCC angiogenesis, growth, and metastasis. In this study, we found palliative liver resection elevated tumor VEGF levels markedly, in accordance with the literature [25]. The alteration of endostatin (a potent angiogenesis inhibitor) and MT1MMP (an activator of MMP2) was minor, which indicated that elevated tumor VEGF and increased MMP2 activity were not directly due to endostatin and MT1MMP, whose detailed molecular mechanism remains to be elucidated.

In most studies, palliative resection for HCC was combined with chemotherapy or biotherapy, such as IFN- $\alpha$ $[21,22]$. Our previous studies revealed that IFN- $\alpha$ inhibited HCC and extended the lifespan of mice and could be attributed to anti-angiogenesis [14,16]; SYY directly down-regulated MMP2 and VEGF and inhibited HCC growth and metastasis [15]. Others also reported that herbal medicine could inhibit the growth of MHCC97H cells used in this study [27] and could inhibit the invasiveness potential of HCC cells via MMP2 inhibition [28]. Based on our in vitro and in vivo studies, we considered that inhibition of the metastasis-enhancing effects due to dysregulation of MMP2/TIMP2 and VEGF might further improve operative efficacy in patients with HCC. Fortunately, the study showed that 
combined therapy with SYY plus IFN- $\alpha$ was more effective than any single agent on residual HCC following palliative resection. This inhibitory effect of combined therapy on progression of preexisting $\mathrm{HCC}$ was partially associated with a decreased VEGF level and lower MVD, which is in keeping with recent experimental evidence that growth of small nests of cells can be stunted by a variety of agents that have the common ability to inhibit angiogenesis [29]. Moreover, in our study, the side effects of therapy in mice were well tolerated $[14,15]$. The weight changes in mice observed in this research showed that SSY and the combined therapy noticeably minimized BW loss at the fifth week after treatment, which suggested that we should administer herbal medicine for a long period. Consequently, more attention should be paid to the active role of Chinese herbal medications in combination therapy for patients with HCC [30].

We are also aware of some limitations in our study. First, we could not sufficiently elucidate the exact mechanism of the metastasis-enhancing potential of residual tumor. Further basic research for the stimulating effect is needed. Second, we did not offer a detailed explanation for how SYY reinforced IFN- $\alpha$ to inhibit HCC. Third, because the study used nude mice the ability to provide robust evidence is limited. Therefore, large-scale, multicenter, placebo-controlled, and prospective studies are needed to test our results. Despite these limitations, we believe that the current study provides preliminary and powerful data to support future evaluation of SYY in combination with IFN- $\alpha$ for HCC in a large cohort, randomized clinical trial that has been performed in Zhongshan Hospital of Fudan University, Shanghai, PR China.

In summary, palliative resection induced the metastasis-enhancing potential of residual HCC via breakdown of the MMP2/TIMP2 balance and up-regulation of VEGF, but the precise mechanism of this stimulating effect remains to be elucidated. Combination therapy with SYY plus IFN- $\alpha$, by regulating the MMP2/TIMP2 ratio and VEGF expression, could be an effective therapeutic strategy to reverse the tumor-enhancing effect derived from hepatectomy. The results indicate the potential use of this therapy to improve the postoperative prognosis of patients with HCC.

\section{Conclusions}

This study showed that palliative resection-accelerated HCC metastasis may be attributed, in part, to up-regulation of VEGF and MMP2/TIMP2; SYY reinforced IFN- $\alpha$ to inhibit the metastasis-enhancing potential. Therefore, the combined therapy of SYY plus IFN- $\alpha$ may be used after hepatectomy for patients with HCC.

\section{Abbreviations}

HCC: hepatocellular carcinoma; IFN- $\alpha$ : interferon-alfa-1b; MMP2: matrix metalloproteinase 2; TIMP2: tissue inhibitor of metalloproteinase 2; MT1MMP: membrane type 1-matrix metalloproteinase; VEGF: vascular endothelial growth factor; MVD: microvessel density; DMEM: Dulbecco modified Eagle medium

\section{Acknowledgements}

We thank Dr. Yuan Ji, Department of Pathology, Zhongshan Hospital, Fudan University, Shanghai, People's Republic of China, for expert technical assistance. We thank professor Qi-Song Li, Jian Zhou, Sheng-Long Ye, Yu Chao and Jie Chen, Liver Cancer Institute, Zhongshan Hospital, Fudan University, Shanghai, People's Republic of China, for their support in animal studies with SYY. This research project was supported by grants from the Foundation of 6th People's Hospital Affiliated to Shanghai Jiaotong University, Shanghai, PR China (Hospital, No.1131).

\section{Author details}

'Department of General Surgery, 6th People's Hospital of Shanghai, Shanghai Jiaotong University, Shanghai 200233, PR China. ²Department of Radiology, Central Hospital of Shanghai Xuhui District, Shanghai 200031, PR China. ${ }^{3}$ Liver Cancer Institute and Zhongshan Hospital, Fudan University, Shanghai 200032, PR China; Key Laboratory for Carcinogenesis \& Cancer Invasion, the Chinese Ministry of Education, Shanghai 200032, PR China.

\section{Authors' contributions}

QZ and ZYT organized the study, planned the experiments, performed the statistical analysis and helped to write the manuscript. XYH, ZLH, and LW contributed to the design of this study, selected the samples, performed the statistical analysis, and drafted the manuscript. YHX participated in the design and coordination of the study. XYH and KXA contributed to the interpretation of the immunohistochemical data and helped write the manuscript. All authors read and approved the final manuscript.

\section{Competing interests}

The authors declare that they have no competing interests.

Received: 4 May 2010 Accepted: 25 October 2010

Published: 25 October 2010

\section{References}

1. Parkin DM, Bray F, Ferlay J, Pisani P: Global cancer statistics, 2002. CA Cancer J Clin 2005, 55:74-108.

2. Zhou XD, Tang ZY, Ma ZC, Fan J, Wu ZQ, Qin LX, Zhou J, Yu Y, Sun HC, Qiu SJ: Twenty-year survivors after resection for hepatocellular carcinoma-analysis of 53 cases. J Cancer Res Clin Oncol 2009, 135:1067-1072.

3. García-Alonso I, Palomares T, Alonso A, Echenique-Elizondo M, Caramés J, Castro B, Méndez J: Effect of liver resection on the progression and growth of rhabdomyosarcoma metastases in a rat model. J Surg Res 2008, 148:185-190.

4. de Jong KP, Lont HE, Bijma AM, Brouwers MA, de Vries EG, van Veen ML, Marquet RL, Slooff MJ, Terpstra OT: The effect of partial hepatectomy on tumor growth in rats: in vivo and in vitro studies. Hepatology 1995, 22(4 Pt 1):1263-1272.

5. Harun N, Nikfarjam M, Muralidharan V, Christophi C: Liver regeneration stimulates tumor metastases. J Surg Res 2007, 1(38):284-290.

6. Picardo A, Karpoff HM, Ng B, Lee J, Brennan MF, Fong Y: Partial hepatectomy accelerates local tumor growth: Potential roles of local cytokine activation. Surgery 1998, 124:57-64.

7. García-Alonso I, Palomares T, Alonso A, Portugal V, Castro B, Caramés J, Méndez J: Effect of hepatic resection on development of liver metastasis. Rev Esp Enferm Dig 2003, 95:765-776.

8. Yokoyama S, Goto CL, Chen TL, Pan TL, Kawano K, Kitano S: Major hepatic resection may suppress the growth of tumors remaining in the residual liver. Br J Cancer 2000, 83:1096-1101.

9. Castillo MH, Doerr RJ, Paolini N Jr, Cohens S, Goldrosen M: Hepatectomy prolongs survival of mice with induced liver metastases. Arch Surg 1989, 124:167-169.

10. Liu JH, Chen PW, Asch SM, Busuttil RW, Ko CY: Surgery for hepatocellular carcinoma: does it improve survival? Ann Surg Oncol 2004, 11:298-303. 
11. Sun FX, Tang ZY, Liu KD, Ye SL, Xue Q, Gao DM, Ma ZC: Establishment of a metastatic model of human hepatocellular carcinoma in nude mice via orthotopic implantation of histologically intact tissues. Int J Cancer 1996, 66:239-243.

12. Tian J, Tang ZY, Ye SL, Liu YK, Lin ZY, Chen J, Xue Q: New human hepatocellular carcinoma (HCC) cell line with highly metastatic potential (MHCC97) and its expressions of the factors associated with metastasis. Br J Cancer 1999, 81:814-821.

13. Li Y, Tang ZY, Ye SL, Liu YK, Chen J, Xue Q, Chen J, Gao DM, Bao WH: Establishment of cell clones with different metastatic potential from the metastatic hepatocellular carcinoma cell line MHCC97. World J Gastroenterol 2001, 7:630-636.

14. Wang L, Tang ZY, Qin LX, Wu XF, Sun HC, Xue Q, Ye SL: High-dose and long-term therapy with interferon-alfa inhibits tumor growth and recurrence in nude mice bearing human hepatocellular carcinoma xenografts with high metastatic potential. Hepatology 2000, 32:43-48.

15. Huang XY, Wang L, Huang ZL, Zheng Q, Li QS, Tang ZY: Herbal extract "Songyou Yin" inhibits tumor growth and prolongs survival in nude mice bearing human hepatocellular carcinoma xenograft with high metastatic potential. J Cancer Res Clin Oncol 2009, 135:1245-1255.

16. Wang L, Wu WZ, Sun HC, Wu XF, Qin LX, Liu YK, Liu KD, Tang ZY: Mechanism of interferon alpha on inhibition of metastasis and angiogenesis of hepatocellular carcinoma after curative resection in nude mice. J Gastrointest Surg 2003, 7:587-594.

17. Broomfield S, Currie A, van der Most RG, Brown M, van Bruggen I, Robinson BW, Lake RA: Partial, but not complete, tumor-debulking surgery promotes protective antitumor memory when combined with chemotherapy and adjuvant immunotherapy. Cancer Res 2005, 65:7580-7584.

18. Zhou J, Tang ZY, Fan J, Wu ZQ, Ji Y, Xiao YS, Shi YH, Li XM, Sun QM, Liu YK, et al: Capecitabine inhibits postoperative recurrence and metastasis after liver cancer resection in nude mice with relation to the expression of platelet-derived endothelial cell growth factor. Clin Cancer Res 2003, 9(16 Pt 1):6030-6037.

19. Weidner N, Semple JP, Welch WR, Folkman J: Tumor angiogenesis and metastasis-correlation in invasive breast carcinoma. N Engl J Med 1991, 324:1-8.

20. Gotohda N, Kinoshita T, Konishi M, Nakagohri T, Takahashi S, Furuse J, Ishii $\mathrm{H}$, Yoshino $\mathrm{M}$ : New indication for reduction surgery in patients with advanced hepatocellular carcinoma with major vascular involvement. World J Surg 2006, 30:431-438.

21. Nagano H, Miyamoto A, Wada H, Ota H, Marubashi S, Takeda Y, Dono K, Umeshita K, Sakon M, Monden M: Interferon-alpha and 5-fluorouracil combination therapy after palliative hepatic resection in patients with advanced hepatocellular carcinoma, portal venous tumor thrombus in the major trunk, and multiple nodules. Cancer 2007, 110:2493-2501.

22. Nagano $H$, Sakon $M$, Eguchi $H$, Kondo M, Yamamoto $T$, Ota H, Nakamura M, Wada H, Damdinsuren B, Marubashi S, et al: Hepatic resection followed by IFN-alpha and 5-FU for advanced hepatocellular carcinoma with tumor thrombus in the major portal branch. Hepatogastroenterology 2007, 54:172-179.

23. Ye QH, Qin LX, Forgues $M$, He P, Kim JW, Peng AC, Simon R, Li Y, Robles Al, Chen $Y$, et al: Predicting hepatitis $B$ virus-positive metastatic hepatocellular carcinomas using gene expression profiling and supervised machine learning. Nat Med 2003, 9:416-423.

24. Wang Z, Zhou J, Fan J, Qiu SJ, Yu Y, Huang XW, Tang ZY: Effect of rapamycin alone and in combination with sorafenib in an orthotopic model of human hepatocellular carcinoma. Clin Cancer Res 2008, 14:5124-5130.

25. Perry KA, Enestvedt CK, Hosack LW, Pham TH, Diggs BS, Teh S, Orloff S, Winn S, Hunter JG, Sheppard BC: Increased vascular endothelial growth factor transcription in residual hepatocellular carcinoma after open versus laparoscopic hepatectomy in a small animal model. Surg Endosc 2010, 24:1151-1157.

26. Altadill A, Rodríguez M, González LO, Junquera S, Corte MD, GonzálezDieguez ML, Linares A, Barbón E, Fresno-Forcelledo M, Rodrigo L, et al: Liver expression of matrix metalloproteases and their inhibitors in hepatocellular carcinoma. Dig Liver Dis 2009, 41:740-748.

27. Yuan A, Li Z, Li X, Yi S, Wang S, Shi K, Bian J: Distinct effect of Chrysanthemum indicum Linné extracts on isoproterenol-induced growth of human hepatocellular carcinoma cells. Oncol Rep 2009, 22:1357-1363.

28. Ha KT, Kim JK, Kang SK, Kim DW, Lee YC, Kim HM, Kim CH: Inhibitory effect of Sihoga-Yonggol-Moryo-Tang on matrix metalloproteinase-2 and -9 activities and invasiveness potential of hepatocellular carcinoma. Pharmacol Res 2004, 50:279-285.

29. $X u$ Y, Wen Z, Xu Z: Chitosan nanoparticles inhibit the growth of human hepatocellular carcinoma xenografts through an antiangiogenic mechanism. Anticancer Res 2009, 29:5103-5109.

30. Yu Y, Lang $Q$, Chen Z, Li B, Yu C, Zhu D, Zhai X, Ling C: The efficacy for unresectable hepatocellular carcinoma may be improved by transcatheter arterial chemoembolization in combination with a traditional Chinese herbal medicine formula. Cancer 2009, 115:5132-5138.

\section{Pre-publication history}

The pre-publication history for this paper can be accessed here: http://www.biomedcentral.com/1471-2407/10/580/prepub

doi:10.1186/1471-2407-10-580

Cite this article as: Huang et al:: Herbal compound "Songyou Yin" reinforced the ability of interferon-alfa to inhibit the enhanced metastatic potential induced by palliative resection of hepatocellular carcinoma in nude mice. BMC Cancer 2010 10:580.

\section{Submit your next manuscript to BioMed Central and take full advantage of:}

- Convenient online submission

- Thorough peer review

- No space constraints or color figure charges

- Immediate publication on acceptance

- Inclusion in PubMed, CAS, Scopus and Google Scholar

- Research which is freely available for redistribution

Submit your manuscript at www.biomedcentral.com/submit
Biomed Central 